Article

\title{
Simultaneous removal of nitrobenzene and phenol by homogenous catalytic wet air oxidation
}

\author{
Dongmei Fu a,*, Feifang Zhang b, Lianzhi Wang c, Fan Yang a, Xinmiao Liang a \\ a Dalian Institute of Chemical Physics, Chinese Academy of Sciences, Dalian 116023, Liaoning, China \\ b School of Pharmacy, East China University of Science and Technology, Shanghai 200237, China \\ c School of Chemical and Environmental Engineering, Hubei University for Nationalities, Enshi 445000, Hubei, China
}

\section{A R T I C L E I N F O}

Article history:

Received 22 March 2015

Accepted 10 April 2015

Published 20 July 2015

\section{Keywords:}

Catalytic wet air oxidation

Co-oxidation

Homogenous catalyst

Advanced oxidation process

Wastewater treatment

\section{Introduction}

Nitrobenzene (NB) is widely used in the manufacture of different types of industrial products such as dyes, explosives and pesticides. It has also been used as a solvent to make paint, shoes and polishes [1,2]. NB may be released into the environment during its varied uses and, because of its mutagenicity, environmental persistence and tendency to bioaccumulate, NB is listed as one of the priority organic pollutants by the United States Environmental Protection Agency (http:// iaspub.epa.gov/waters10/rpt_epa_num_criteria.run_report).

The direct oxidation of NB can be very difficult because of the low electron density around its benzene ring [3]. During the last two decades, a number of advanced oxidation processes
(AOPs), such as photo-catalytic oxidation [4], ozonation [5], Fenton oxidation [6] and combined oxidation [7,8], have been applied to the degradation of NB. Among these, wet air oxidation (WAO), initially proposed and developed by Zimmermann, appears to show particular potential with regard to wastewater treatment. Unlike other AOPs, WAO is an attractive method for the treatment of waste streams with chemical oxygen demand from 10-100 g/L that are too dilute to incinerate but too concentrated for biological treatment [9]. During WAO, the waste is oxidized into carbon dioxide, water and low molecular weight organic acids at elevated temperatures $\left(150-325{ }^{\circ} \mathrm{C}\right)$ and pressures (0.5-20 $\mathrm{MPa}$ ) using pure oxygen or air as the oxidant $[10,11]$. WAO is not only eco-friendly but also more economical compared with other AOPs that often use harmful

\footnotetext{
* Corresponding author. Tel +86-411-84379541; Fax: +86-411-84379539; E-mail address: fdm@dicp.ac.cn This work was supported by the National Natural Science Foundation of China (21107108 and 21267009) and the Key Project of Knowledge Innovation Program of the Chinese Academy of Sciences (KJCX2-YW-H04).
} 
and/or expensive oxidizing agents, such as ozone and hydrogen peroxide. To achieve the oxidation of pollutants under milder conditions, catalytic wet air oxidation (CWAO) processes have been developed since the 1970s, especially for wastewater treatment [12-14].

In recent years, co-oxidation methods have been increasingly employed to further improve the oxidation efficiency of WAO processes. Willms et al. [15] first observed that the efficiency of m-xylene oxidation increased with the introduction of the more easily oxidizable phenol to the reaction system. Similar results have been reported in which the addition of cellobiose or phenol to solutions containing recalcitrant low molecular weight acids led to enhanced oxidation rates [16]. The degradation rate of thiocyanate was also significantly enhanced when it was simultaneously oxidized with cyanide under the same conditions [17]. We also reported that the presence of phenol in the reaction media greatly improves the conversion of NB $[18,19]$, and that the simultaneous degradation of trichlorophenol and nitrophenol is possible by wet air co-oxidation [20]. Although co-oxidation of pollutants has been previously reported, there has been little investigation of co-oxidation in the presence of catalysts.

Herein we report the first-ever catalytic co-oxidation of NB and phenol using homogenous catalysts. Homogeneous catalytic oxidation was chosen because of its simplicity and effectiveness, although in practice the catalyst, such as $\mathrm{Fe}\left(\mathrm{SO}_{4}\right)_{2}$, $\mathrm{Cu}\left(\mathrm{NO}_{3}\right)_{2}, \mathrm{Ni}\left(\mathrm{NO}_{3}\right)_{2}, \mathrm{Co}\left(\mathrm{NO}_{3}\right)_{2}$ or $\mathrm{Ce}\left(\mathrm{NO}_{3}\right)_{3}$, must be removed or recovered from the treated effluent afterwards to prevent the contamination of the receiving water. The aim of the present work was to gain insights into simultaneous catalytic NB and phenol oxidation, and to provide a working strategy for the degradation of refractory compounds by the batch addition of an initiator. We also expect this strategy to be useful with other active heterogeneous catalysts in the future as a means of accomplishing the economical and environmentally friendly oxidation of pollutants.

\section{Experimental}

\subsection{Materials and reagents}

NB and phenol were purchased from Sigma-Aldrich Chemicals. All other chemicals were of analytical grade and were obtained from the Shanghai Chemicals Co. (China), while the solvents were all high performance liquid chromatography (HPLC) grade. Water was prepared with a Milli-Q water purification system (Millipore, Milford, MA) for use in all experimental trials.

\subsection{Catalytic wet air oxidation}

The reactor was made of stainless steel (SS316) and had an inner volume of $400 \mathrm{~mL}$, and the instrument structure was illustrated in a previous publication [18]. The reaction temperature was measured using a thermocouple and controlled by an intelligent regulator. The autoclave was charged with $200 \mathrm{~mL}$ of an aqueous solution in which the initial concentrations of NB and phenol were 400 and $800 \mathrm{mg} / \mathrm{L}$, respectively. The reactor was subsequently pressurized with pure nitrogen to a pressure of 5.0 MPa and this pressure was maintained for 3 min after which the autoclave was evacuated to $0.1 \mathrm{MPa}$. This step was repeated three times to make sure that the original oxygen in the reactor was replaced with nitrogen. The reactor was then pressurized to 4.0 MPa with nitrogen and heated to the desired reaction temperature. Once this temperature was reached, pure oxygen (the pressure of which was determined using the equation $p V=n R T$ ) was supplied to the reactor and the reaction time was counted from this "zero" point. The stir speed was set at $500 \mathrm{rpm}$ to allow for vigorous mixing so as to ensure that the oxidation rate was not controlled by mass transfer effects. Liquid samples were periodically withdrawn and analyzed for phenol and NB levels.

\subsection{Analysis}

The liquid phase aliquots were analyzed by HPLC (Waters 2690-996 with a photodiode array detector) using a Kromasil C18 column (250 mm $\times 4.6 \mathrm{~mm}, 5 \mu \mathrm{m})$. The chromatograph was calibrated with standard solutions of NB and phenol in the range of 0 to $500 \mathrm{mg} / \mathrm{L}$ and 0 to $1000 \mathrm{mg} / \mathrm{L}$, respectively, producing calibration curves with $\mathrm{R}^{2}$ values greater than 0.999 . The mobile phase was a $60 / 40(\mathrm{~V} / \mathrm{V})$ water/methanol mixture in the isocratic mode with detection at an absorbance wavelength of $265 \mathrm{~nm}$. The flow rate was set to $1.0 \mathrm{~mL} / \mathrm{min}$, and the injection volume was $10 \mu \mathrm{L}$. Under these conditions, the retention time of the NB and phenol was 7.3 and $12.9 \mathrm{~min}$, respectively.

\section{Results and discussion}

\subsection{Effect of $\mathrm{Cu}^{2+}$ on the catalytic co-oxidation of $\mathrm{NB}$}

It has been reported that $\mathrm{Cu}^{2+}$ shows good catalytic effects during the WAO of pollutants [13]. Therefore, in this work, we initially assessed $\mathrm{Cu}^{2+}$ as a homogeneous catalyst for the co-oxidation of $\mathrm{NB}$ and phenol. In a typical trial, a $\mathrm{Cu}\left(\mathrm{NO}_{3}\right)_{2}$ solution ( $2 \mathrm{~mL}, 0.2 \mathrm{~mol} / \mathrm{L}$ ) was added to $200 \mathrm{~mL}$ of a solution of $\mathrm{NB}$ and phenol, to produce a final $\mathrm{Cu}^{2+}$ concentration of 2 mmol/L. Under these conditions, a NB conversion of $91 \%$ was achieved after $1 \mathrm{~h}$ at $200{ }^{\circ} \mathrm{C}$ in the presence of phenol, while only $22 \%$ NB conversion was observed without phenol under the same conditions. In contrast, a previous study by our group found minimal NB conversion in the presence of phenol at 200 ${ }^{\circ} \mathrm{C}$, with only slight improvements to $24 \%$ and $27 \%$ at 210 and $220{ }^{\circ} \mathrm{C}$ [16]. It therefore can be concluded that $\mathrm{Cu}\left(\mathrm{NO}_{3}\right)_{2}$ is indeed a very active catalyst for the co-oxidation of NB. Given this promising result, we expanded our efforts and screened a number of other homogenous catalysts for the co-oxidation of NB and phenol, examining the effects of the catalyst and the presence of phenol.

\subsection{Effect of different homogenous catalysts}

The effects of the homogenous catalysts $\mathrm{Fe}\left(\mathrm{SO}_{4}\right)_{2}, \mathrm{Ni}\left(\mathrm{NO}_{3}\right)_{2}$, 
$\mathrm{Co}\left(\mathrm{NO}_{3}\right)_{2}$ and $\mathrm{Ce}\left(\mathrm{NO}_{3}\right)_{3}$ during the catalytic co-oxidation of $\mathrm{NB}$ and phenol were studied at $200{ }^{\circ} \mathrm{C}$ with the a final metal concentration of $2 \mathrm{mmol} / \mathrm{L}$. The other reaction conditions remained the same as those detailed in the prior section in which $\mathrm{Cu}\left(\mathrm{NO}_{3}\right)_{2}$ was used as the catalyst. Fig. 1 shows the catalytic NB conversion in the presence of phenol (that is, the catalytic co-oxidation of NB) and in absence of phenol (the catalytic single oxidation of NB) after $1 \mathrm{~h}$ of reaction time. Following the single catalytic oxidation, NB conversions of $11 \%, 22 \%, 36 \%$, $18 \%$ and $18 \%$ were obtained when using $\mathrm{Fe}\left(\mathrm{SO}_{4}\right)_{2}, \mathrm{Cu}\left(\mathrm{NO}_{3}\right)_{2}$, $\mathrm{Ni}\left(\mathrm{NO}_{3}\right)_{2}, \mathrm{Co}\left(\mathrm{NO}_{3}\right)_{2}$ and $\mathrm{Ce}\left(\mathrm{NO}_{3}\right)_{3}$ as the catalysts, respectively. In comparison, only 3\% NB conversion was found without catalysts under the same conditions [19]. Among these five homogenous catalysts, $\mathrm{Cu}\left(\mathrm{NO}_{3}\right)_{2}$ and $\mathrm{Ni}\left(\mathrm{NO}_{3}\right)_{2}$ provided the best catalytic activity. Because NB is a refractory pollutant, it is very difficult to be degraded and, even using $\mathrm{Cu}\left(\mathrm{NO}_{3}\right)_{2}$ and $\mathrm{Ni}\left(\mathrm{NO}_{3}\right)_{2}$ as the catalysts, the conversion was not sufficiently high. As seen in Fig. 1, in the presence of phenol, the NB conversions following $1 \mathrm{~h}$ of oxidation at $200{ }^{\circ} \mathrm{C}$ were $11 \%, 91 \%, 82 \%, 61 \%$ and $14 \%$ when employing $\mathrm{Fe}\left(\mathrm{SO}_{4}\right)_{2}, \mathrm{Cu}\left(\mathrm{NO}_{3}\right)_{2}, \mathrm{Ni}\left(\mathrm{NO}_{3}\right)_{2}$, $\mathrm{Co}\left(\mathrm{NO}_{3}\right)_{2}$ and $\mathrm{Ce}\left(\mathrm{NO}_{3}\right)_{3}$ as the catalysts. It is clear, therefore, that the conversion of NB during co-oxidation with phenol is increased significantly by the introduction of catalysts.

Fig. 2 summarizes the phenol conversions during the catalytic co-oxidation with NB. It can be seen that conversions after $1 \mathrm{~h}$ of degradation at $200{ }^{\circ} \mathrm{C}$ were $50 \%, 100 \%, 99 \%, 89 \%$ and $54 \%$ when using $\mathrm{Fe}\left(\mathrm{SO}_{4}\right)_{2}, \mathrm{Cu}\left(\mathrm{NO}_{3}\right)_{2}, \mathrm{Ni}\left(\mathrm{NO}_{3}\right)_{2}, \mathrm{Co}\left(\mathrm{NO}_{3}\right)_{2}$ and $\mathrm{Ce}\left(\mathrm{NO}_{3}\right)_{3}$, respectively. It is believed that, in the co-oxidation reaction, the phenol generates either active radicals or intermediates. Because phenol was evidently not degraded efficiently when applying $\mathrm{Fe}\left(\mathrm{SO}_{4}\right)_{2}$ or $\mathrm{Ce}\left(\mathrm{NO}_{3}\right)_{3}$ as the catalysts, the phenol did not provide sufficient radicals or intermediates to initiate NB degradation in conjunction with these catalysts. However, when combined with $\mathrm{Cu}\left(\mathrm{NO}_{3}\right)_{2}$ or $\mathrm{Ni}\left(\mathrm{NO}_{3}\right)_{2}$, phenol was completely degraded, thus presumably yielding active radicals or intermediates that in turn supported the oxidation of NB.

\subsection{Effect of temperature on the catalytic co-oxidation of $N B$}

The catalytic co-oxidation of NB (400 mg/L) in the presence

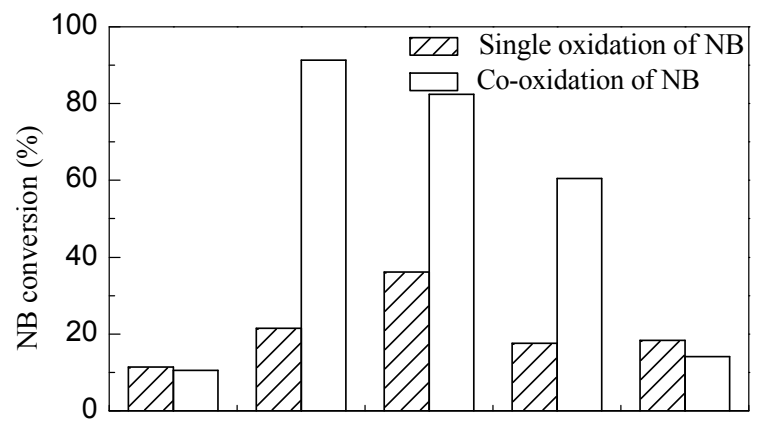

$\mathrm{Fe}\left(\mathrm{SO}_{4}\right)_{2} \quad \mathrm{Cu}\left(\mathrm{NO}_{3}\right)_{2} \quad \mathrm{Ni}\left(\mathrm{NO}_{3}\right)_{2} \quad \mathrm{Co}\left(\mathrm{NO}_{3}\right)_{2} \mathrm{Ce}\left(\mathrm{NO}_{3}\right)_{3}$

Fig. 1. Conversion of NB during single oxidation and co-oxidation with phenol when using different homogenous catalysts. Experimental conditions: $C_{\text {phenol }}=800 \mathrm{mg} / \mathrm{L}, C_{\mathrm{NB}}=400 \mathrm{mg} / \mathrm{L}, P_{02}=1.0 \mathrm{MPa}, C_{\text {catalyst }}=2$ $\mathrm{mmol} / \mathrm{L}, T=200^{\circ} \mathrm{C}, t=1 \mathrm{~h}$.

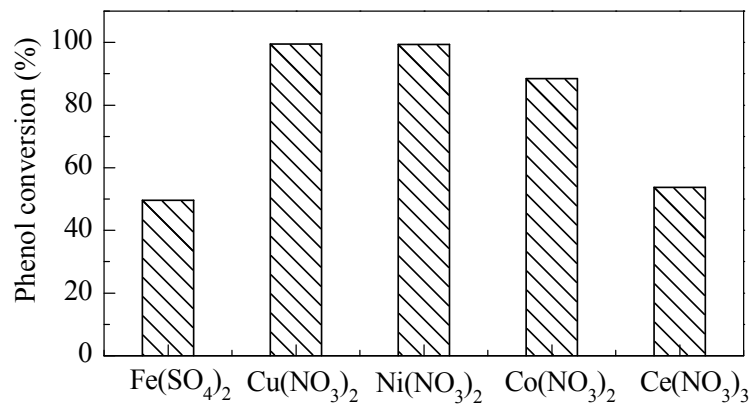

Fig. 2. Phenol conversions during co-oxidation with nitrobenzene with various homogenous catalysts. Experimental conditions: $C_{\text {phenol }}=800$ $\mathrm{mg} / \mathrm{L}, C_{\mathrm{NB}}=400 \mathrm{mg} / \mathrm{L}, P_{02}=1.0 \mathrm{MPa}, C_{\text {catalyst }}=2 \mathrm{mmol} / \mathrm{L}, T=200{ }^{\circ} \mathrm{C}, t=$ $1 \mathrm{~h}$.

of phenol (800 mg/L) was performed under 1.0 MPa oxygen partial pressure with $\mathrm{Cu}\left(\mathrm{NO}_{3}\right)_{2}$ as the catalyst at $150-200{ }^{\circ} \mathrm{C}$ to examine the effect of temperature on the degradation reaction. Table 1 presents the results for the catalytic NB conversion and associated color changes obtained when performing the reaction both with and without phenol. It appears that temperature had little effect on the conversion of NB in the catalytic co-oxidation process, because good conversion was obtained throughout the temperature range. Even at $150{ }^{\circ} \mathrm{C}$, the conversion of NB during the co-oxidation process reached $87 \%$ after 1 h. With increasing temperature, the conversion values were $88 \%, 90 \%, 90 \%$ and $91 \%$ at $160,170,180$ and $200{ }^{\circ} \mathrm{C}$, respectively. In the case of single catalytic NB oxidation, however, the conversions were only $6 \%$ and $7 \%$ at 170 and $180{ }^{\circ} \mathrm{C}$, respectively, and even at $200{ }^{\circ} \mathrm{C}$, the conversion was only $22 \%$. Additionally, over the temperature range studied, the conversion of phenol was always more than $99 \%$. Nevertheless, temperature was found to have a notable effect on the intermediate products.

The color change of the solution after the catalytic co-oxidation at different temperatures indicated that intermediate products were degraded to a greater extent at elevated temperatures. The solution following degradation at $150{ }^{\circ} \mathrm{C}$ was brown, indicating that quinone was formed while, at 160 ${ }^{\circ} \mathrm{C}$, the solution turned light yellow with some dark sediment visible after degradation. As the temperature was further increased, the solution became almost colorless and the sediment gradually disappeared. At $200{ }^{\circ} \mathrm{C}$, the post-reaction solution was clear and colorless and there was only a minimal amount of sediment, indicating that the quinone and other insoluble intermediates were almost completely degraded. The quality of the effluent thus improved as the temperature was increased, especially above $180^{\circ} \mathrm{C}$.

We also studied the co-oxidation process using $\mathrm{Ni}\left(\mathrm{NO}_{3}\right)_{2}(2$ $\mathrm{mmol} / \mathrm{L}$ ) as the catalyst over the temperature range of $160-210^{\circ} \mathrm{C}$ after $2 \mathrm{~h}$ reaction. It is clear from Fig. 3 that temperature had a more prominent effect, such that the NB conversions were $8 \%, 36 \%$ and $75 \%$ at 160,170 and $180{ }^{\circ} \mathrm{C}$, respectively. However, when the temperature was further increased to $190{ }^{\circ} \mathrm{C}$, the NB conversion fell to $51 \%$ and further decreased to $34 \%$ at $210{ }^{\circ} \mathrm{C}$. We propose that the active radicals or intermediates formed during the phenol oxidation in the 
Table 1

$\mathrm{NB}$ oxidation catalyzed by $\mathrm{Cu}\left(\mathrm{NO}_{3}\right)_{2}$ at different temperatures after $1 \mathrm{~h}$

\begin{tabular}{|c|c|c|c|c|c|}
\hline \multirow{2}{*}{$\begin{array}{l}\text { Temperature } \\
\left({ }^{\circ} \mathrm{C}\right)\end{array}$} & \multicolumn{3}{|c|}{ Catalytic co-oxidation } & \multicolumn{2}{|c|}{ Catalytic single oxidation } \\
\hline & Solution property after reaction & Phenol conversion (\%) & NB Conversion (\%) & Solution color after reaction & NB Conversion (\%) \\
\hline 150 & Brown & 99 & 87 & $-{ }^{*}$ & $-{ }^{*}$ \\
\hline 160 & Light yellow, dark sediment & 99 & 88 & -* & $-^{*}$ \\
\hline 170 & Colorless, less dark sediment & 100 & 90 & Colorless & 6 \\
\hline 180 & Colorless, less dark sediment & 100 & 90 & Colorless & 7 \\
\hline 200 & Colorless, minimal sediment & 100 & 91 & Yellow-green & 22 \\
\hline
\end{tabular}

*Without detection.

co-oxidation process were degraded at higher temperatures, thus they could not initiate NB degradation efficiently under such conditions. This could explain why the NB conversion actually decreased at higher temperatures with phenol using $\mathrm{Ni}\left(\mathrm{NO}_{3}\right)_{2}$ as the catalyst. The optimal temperature for the catalytic co-oxidation of $\mathrm{NB}$ with $\mathrm{Ni}\left(\mathrm{NO}_{3}\right)_{2}$ as catalyst was thus 180 ${ }^{\circ} \mathrm{C}$. Compared with $\mathrm{Ni}\left(\mathrm{NO}_{3}\right)_{2}, \mathrm{Cu}\left(\mathrm{NO}_{3}\right)_{2}$ was clearly a better catalyst for catalytic co-oxidation of NB because it allowed a greater degree of NB conversion (about 90\%) in a shorter reaction time $(1 \mathrm{~h})$.

\subsection{Effect of the phenol addition mode}

In the previous study, it was found that the conversion of $\mathrm{NB}$ could not be further increased once the co-oxidation of phenol was completed, and that the conversion plot would appears as a platform thereafter [18]. This observation led us to believe that we could increase the NB conversion by adding the phenol to the NB solution in multiple, small amounts to allow the active radicals or intermediates formed by phenol oxidation to continuously initiate the NB oxidation. To test this hypothesis, following a $60 \mathrm{~min}$ oxidation of solely $\mathrm{NB}$, we added $10 \mathrm{~mL}$ of phenol solution $(16 \mathrm{~g} / \mathrm{L})$ to $200 \mathrm{~mL}$ of the NB solution $(400$ $\mathrm{mg} / \mathrm{L}$ ) using a high pressure pump with an injection rate of 0.5 $\mathrm{mL} / \mathrm{min}$. This trial generated final concentrations of $\mathrm{NB}$ and phenol of 381 and $762 \mathrm{mg} / \mathrm{L}$, respectively, the total amount of phenol added (160 $\mathrm{mg}$ ) being the same as added during the original co-oxidation of NB and phenol as described above. Subsequently, equal amounts of phenol were added as a single $10 \mathrm{~mL}$ aliquot, two $5 \mathrm{~mL}$ aliquots, or three aliquots of 3,4 and 3 $\mathrm{mL}$ and the NB conversion was recorded after $3 \mathrm{~h}$ at $200^{\circ} \mathrm{C}$. The

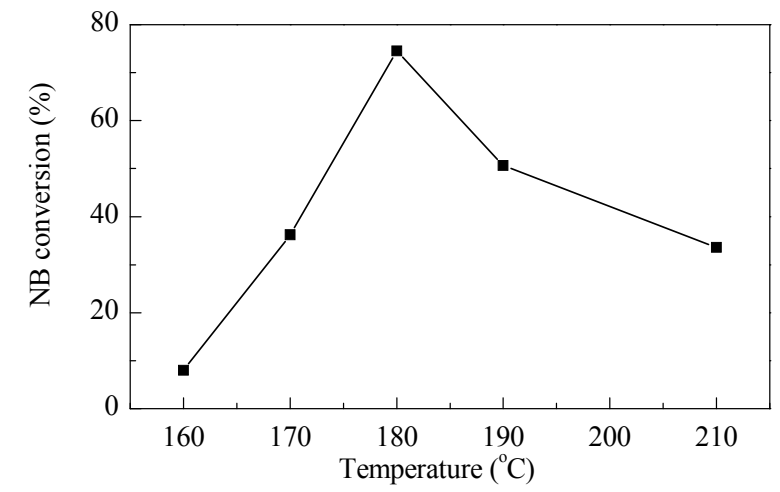

Fig. 3. Effect of temperature on the wet air co-oxidation of NB with phenol using $\mathrm{Ni}\left(\mathrm{NO}_{3}\right)_{2}$ as the catalyst. $C_{\text {phenol }}=800 \mathrm{mg} / \mathrm{L}, C_{\mathrm{NB}}=400$ $\mathrm{mg} / \mathrm{L}, P_{02}=1.0 \mathrm{MPa}, C_{\mathrm{Ni}(\mathrm{NO} 3) 2}=2 \mathrm{mmol} / \mathrm{L}, t=2 \mathrm{~h}$. results were shown in Table 2 . Adding the phenol $(10 \mathrm{~mL})$ at the beginning of the reaction gave an NB conversion of only $36 \%$, while addition of the phenol as a single aliquot after 60 min of degradation increased the conversion of NB to $71 \%$. This result indicated that the active free radicals or intermediates produced by phenol were present over a longer time span, thus more effectively facilitating the conversion of NB. Addition of the same amount of phenol in two or three aliquots further increased the NB conversion to $84 \%$ and $88 \%$, respectively.

The effect of the phenol addition mode on the catalytic co-oxidation of $\mathrm{NB}$ was also studied using $\mathrm{Cu}\left(\mathrm{NO}_{3}\right)_{2}(2 \mathrm{mmol} / \mathrm{L})$ as the catalyst, generating final concentrations of NB and phenol of 381 and $762 \mathrm{mg} / \mathrm{L}$, respectively. Following a $1 \mathrm{~h}$ reaction period at $200{ }^{\circ} \mathrm{C}$, the conversion of NB increased to $95 \%$ when phenol was added in two portions, while $91 \%$ conversion of NB was obtained when all the phenol was introduced in a single portion at the beginning of the reaction (Table 1). The color of the solution after the reaction with two additions of phenol was colorless with no dark intermediates. However, the single phenol addition reaction solution still had a small amount of sediment even the solution became colorless (Table 1). This result demonstrated that the addition of phenol in smaller portions resulted in more effective degradation of the intermediates produced during the NB oxidation. Additionally, the phenol itself was completely converted following the reaction. The above results, taken together, demonstrated that adding phenol in small portions, if combined with the use of a catalyst, can substantially increase the NB conversion.

\section{Conclusions}

$\mathrm{Cu}^{2+}, \mathrm{Co}^{2+}$ and $\mathrm{Ni}^{2+}$ are effective homogeneous catalysts for the co-oxidation of NB and phenol, and among these, $\mathrm{Cu}^{2+}$ is the best. The addition of phenol to the oxidation system in small portions also helps to increase the NB conversion. The conver-

Table 2

Influence of phenol addition mode on wet air co-oxidation of NB at 200 ${ }^{\circ} \mathrm{C}$ after $3 \mathrm{~h}$

\begin{tabular}{lc}
\hline How phenol was added & $\begin{array}{c}\text { NB conversion } \\
(\%)\end{array}$ \\
\hline $\begin{array}{l}\text { phenol was added at the beginning of the reaction, } 10 \\
\mathrm{~mL}\end{array}$ & 36 \\
single batch, after 60 min degradation of NB, $10 \mathrm{~mL}$ & 71 \\
two batches, after $\quad \begin{array}{l}60 \text { min degradation of NB, } 5 \mathrm{~mL} \\
120 \text { min degradation of NB, } 5 \mathrm{~mL}\end{array}$ & 84 \\
three batches, after $\quad \begin{array}{l}60 \text { min degradation of NB, } 3 \mathrm{~mL} \\
90 \text { min degradation of } \mathrm{NB}, 4 \mathrm{~mL}\end{array}$ & 88 \\
& 140 min degradation of $\mathrm{NB}, 3 \mathrm{~mL}$ \\
\hline
\end{tabular}




\section{Graphical Abstract}

Chin. J. Catal., 2015, 36: 952-956 doi: 10.1016/S1872-2067(15)60835-X

Simultaneous removal of nitrobenzene and phenol by homogenous catalytic wet air oxidation

Dongmei Fu*, Feifang Zhang, Lianzhi Wang, Fan Yang, Xinmiao Liang Dalian Institute of Chemical Physics, Chinese Academy of Sciences; East China University of Science and Technology;

Hubei University for Nationalities

Batch-wise addition of phenol together with the use of homogeneous catalysts significantly improves the conversion of nitrobenzene. This oxidation process should provide an alternative and effective means of treating other organic pollutants in the environment.

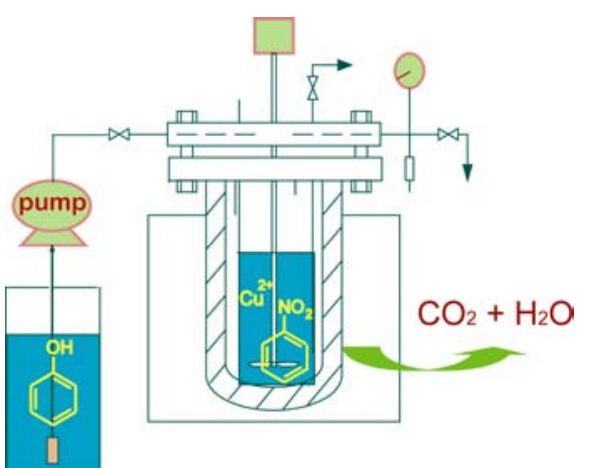

sion of NB reaches $95 \%$ with two batches phenol additions after $1 \mathrm{~h}$ when using $\mathrm{Cu}^{2+}$ solution $(2 \mathrm{mmol} / \mathrm{L})$ as the catalyst at $200{ }^{\circ} \mathrm{C}$ and $1.0 \mathrm{MPa}$ oxygen pressure and complete conversion of phenol was observed after the reaction. The resulting post-reaction solution was clear and colorless. In summary, we have developed a novel catalytic co-oxidation method with batch-wise addition of the phenol initiator. This technique should provide an alternative and effective means of treating other organic pollutants in the environment.

\section{References}

[1] Mu Y, Yu H Q, Zheng J C, Zhang S J, Sheng G P. Chemosphere, 2004, 54: 789

[2] Latifoglu A, Gurol M D. Water Res, 2003, 37: 1879

[3] Li Y P, Cao H B, Liu C M, Zhang Y. J Hazard Mater, 2007, 148: 158

[4] Yuan J, Lü Y K, Li Y, Li J P. Chin J Catal (袁进, 吕永康, 李裕, 李进 平), 2010, 31:597

[5] Restivo J, Rocha R P, Silva A M T, Orfao J J M, Pereira M F R, Figueiredo J L. Chin J Catal (催化学报), 2014, 35: 896

[6] Chamarro E, Marco A, Esplugas S. Water Res, 2001, 35: 1047
[7] Contreras S, Rodriguez M, Chamarro E, Esplugas S, Casado J. Water Sci Technol, 2001, 44: 39

[8] Bandy J, Shemer H, Linden K G. Environ Eng Sci, 2009, 26: 973

[9] Kim K H, Ihm S K. J Hazard Mater, 2011, 186: 16

[10] Luck F. Catal Today, 1999, 53: 81

[11] Oller I, Malato S, Sanchez-Perez J A. Sci Total Environ, 2011, 409: 4141

[12] Suarez-Ojeda M E, Stüber F, Fortuny A, Fabregat A, Carrera J, Font J. Appl Catal B: Environ, 2005, 58: 105

[13] Levec J, Pintar A. Catal Today, 2007, 124: 172

[14] Fu J, Kyzas G Z. Chin J Catal (催化学报), 2014, 35: 1

[15] Willms R S, Reible D D, Wetzel D M, Harrison D P. Ind Eng Chem Res, 1987, 26: 606

[16] Birchmeier M J, Hill C G, Houtman C J, Atalla R H, Weinstock I A. Ind Eng Chem Res, 2000, 39: 55

[17] Oulego P, Collado S, Laca A, Diaz M. J Hazard Mater, 2014, 280: 570

[18] Fu D M, Chen J P, Liang X M. Chemosphere, 2005, 59: 905

[19] Fu D M, Liu R H, Xu Q, Xue X Y, Zhang F F, Liang X. M. Fresenius Environ Bull, 2007, 16: 71

[20] Fu D M, Peng Y R, Liu R H, Zhang F F, Liang X M. Chemosphere, 2009, 75: 701

\section{催化湿式共氧化法同时去除硝基苯和苯酚

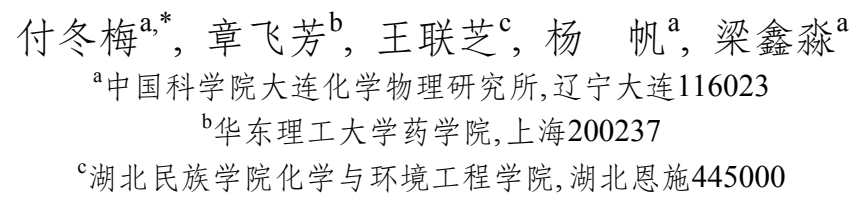

摘要: 在 $150-210^{\circ} \mathrm{C}, 1.0 \mathrm{MPa}$ 氧分压条件下, 对催化湿式共氧化法同时去除硝基苯和苯酚进行了研究. 与无催化剂共氧化降解苯 酚和硝基苯相比,均相催化剂的加入极大提高了苯酚和硝基苯的去除. 在所研究的过渡金属催化剂中, $\mathrm{Cu}^{2+}, \mathrm{Co}^{2+}$ 和 $\mathrm{Ni}^{2+}$ 是有效的催 化剂, 其中 $\mathrm{Cu}^{2+}$ 的催化活性最好. 引发剂苯酚的连续加入模式对硝基苯的去除有很大的促进作用,分批加入苯酚的促进作用更明 显. 在 $200^{\circ} \mathrm{C}$, 以 $\mathrm{Cu}^{2+}$ 为催化剂, 苯酚分两次加入, 反应 $1 \mathrm{~h}$, 硝基苯去除率达到 $95 \%$. 这种催化共氧化体系以及分批进样引发剂的反应 模式对有效去除环境中其它有机污染物提供了一种方法.

关键词：催化湿式氧化；共氧化；均相催化剂；高级氧化技术；废水处理

收稿日期: 2015-03-22. 接受日期: 2015-04-10. 出版日期: 2015-07-20.

*通讯联系人. 电话: (0411)84379541; 传真: (0411)84379539; 电子信箱: fdm@dicp.ac.cn

基金来源：国家自然科学基金(21107108和21267009); 中国科学院知识创新工程(KJCX2-YW-H04).

本文的英文电子版由Elsevier出版社在ScienceDirect上出版(http://www.sciencedirect.com/science/journal/18722067). 